\section{Е.Н. Мастеница}

Актуальные проблемы освоения культурного наследия, музеологии, проектирования экспозиций и выставок на страницах учебных пособий петербургских музеологов

doi:10.31518/2618-9100-2021-2-19

УДК [069.01+069.5]:378.016(470.23-25)

Выходные данные для цитирования:

Мастеница Е.H. Актуальные проблемы освоения культурного наследия, музеологии, проектирования экспозиций и выставок на страницах учебных пособий петербургских музеологов // Исторический курьер. 2021. № 2 (16). C. 223-232. URL: http://istkurier.ru/data/2021/ ISTKURIER-2021-2-19.pdf
E.N. Mastenitsa*

\section{Relevant Problems of the Cultural Heritage Development, Museology, Museum and Exhibition Design in the Pages of Textbooks by Saint Petersburg Museologists}

\author{
doi:10.31518/2618-9100-2021-2-19
}

How to cite:

Mastenitsa E.N. Relevant Problems of the Cultural Heritage Development, Museology, Museum and Exhibition Design in the Pages of Textbooks by Saint Petersburg Museologists // Historical Courier, 2021, No. 2 (16), pp. 223-232. [Available online:] http://istkurier.ru/data/2021/ISTKURIER2021-2-19.pdf

Abstract. The activities of museums all over the world and in Russia have an important social and cultural significance, play an essential role in preservation and transmission of cultural heritage, in educational process, in organization of leisure. The number of Institutions that train professionals for its implementation is expanding. The purpose of the publication is to reveal the intention and structure of textbooks created by authors' teams of the Department of Museology and Cultural Heritage of the St. Petersburg State Institute of Culture, in the context of the conceptual and theoretical views of the emerging scientific school of St. Petersburg museology. The textbook "Cultural Heritage and Museum in the XXI Century" (2018) is intended for masters studying in the educational programs of the Federal State Educational Standard in the direction 51.04.04 "Museology and protection of cultural and natural heritage sites". It summarizes and structures extensive material devoted to the formation of ideas about the heritage and the museum, their historical interconnection and interdependence. The focus is on the ongoing transformations of traditional cultural institutions. Special emphasis is placed on modern value-oriented trends in the development of attitudes towards heritage, as well as on the ideological postulate associated with the understanding of cultural heritage as the foundation and the most important mechanism for the functioning of culture. Many materials, including the works of foreign researchers not previously introduced into scientific circulation and not translated into Russian, have scientific novelty. The textbook "Designing Museum Expositions and Exhibitions: History-Theory-Practice" (2020) is addressed for bachelors mastering the educational program of the Federal State Educational Standard in the direction 51.03.04 "Museology and protection of cultural and natural heritage objects". The presentation of the basics of design is practice-oriented. Their development should contribute to the formation of exhibiting as an area of museum activity, the formation of a new generation of museologists capable of responding to the challenges of the time, thinking creatively and independently solving professional problems.

Keywords: cultural heritage; museum; museology; design; exposure; exhibition; textbook; Saint-Petersburg State Institute of Culture.

The article has been received by the editor on 05.01.2021.

Full text of the article in Russian and references in English are available below.

\footnotetext{
* Мастеница Елена Николаевна, кандидат исторических наук, Санкт-Петербургский государственный институт культуры, Санкт-Петербург, Россия, e-mail: elenamast@yandex.ru

Mastenitsa Elena Nikolaevna, Candidate of Historical Sciences, St. Petersburg State Institute of Culture, St. Petersburg, Russia, e-mail: elenamast@yandex.ru
} 
Аннотация. Деятельность музеев во всем мире и в России имеет важное социокультурное значение, играет существенную роль в сохранении и трансляции культурного наследия, в образовательном процессе, в организации досуга. Расширяется круг высших учебных заведений, осуществляющих подготовку профессионалов для ее реализации. Цель публикации состоит в том, чтобы раскрыть замысел и структуру учебных пособий, созданных авторскими коллективами преподавателей кафедры музеологии и культурного наследия Санкт-Петербургского государственного института культуры, в контексте концептуальнотеоретических воззрений формирующейся научной школы петербургской музеологии. Учебник «Культурное наследие и музей в XXI веке» (2018) предназначен магистрам, обучающимся по образовательным программам ФГОС по направлению 51.04.04 «Музеология и охрана объектов культурного и природного наследия». В нем обобщен и структурирован обширный материал, посвященный формированию представлений о наследии и музее, их исторической взаимосвязи и взаимообусловленности. Фокус внимания сосредоточен на происходящих сегодня трансформациях традиционных культурных институций. Особый акцент сделан на современные ценностно ориентированные тенденции развития отношения к наследию, а также на мировоззренческий постулат, связанный с пониманием культурного наследия как фундамента и важнейшего механизма функционирования культуры. Многие материалы, включая не введенные ранее в научный оборот и не переведенные на русский язык труды зарубежных исследователей, обладают научной новизной. Учебник «Проектирование музейных экспозиций и выставок: история - теория - практика» (2020) адресован бакалаврам, осваивающим образовательную программу ФГОС по направлению 51.03 .04 «Музеология и охрана объектов культурного и природного наследия». Изложение основ проектирования носит практикоориентированный характер. Их освоение должно способствовать становлению экспонирования как ведущего направления музейной деятельности, формированию нового поколения музеологов, способных отвечать вызовам времени, креативно мыслить и самостоятельно решать профессиональные задачи.

Ключевые слова: культурное наследие; музей; музеология; проектирование; экспозиция; выставка; учебное пособие; Санкт-Петербургский государственный институт культуры.

Музеи и музейная деятельность в начале XXI в. переживают существенные трансформации в своем содержании и формах, что отражает происходящие кардинальные изменения в социуме и культуре, вызванные процессами глобализации и становления информационного общества. Очевидно, что деятельность музеев во всем мире и в России имеет важное социокультурное значение, играет существенную роль в образовательном процессе, в организации досуга. Неуклонно расширяется круг высших учебных заведений, осуществляющих подготовку профессионалов для ее реализации. При всем многообразии концептуальных и методических подходов в данной области можно констатировать тот факт, что процесс подготовки будущих музеологов обеспечен учебной литературой, однако она не всегда оперативно и полно отражает те необратимые изменения, которые происходят в науке и практике.

В силу указанных причин коллектив кафедры музеологии и культурного наследия СанктПетербургского государственного института культуры выдвинул в качестве приоритетной задачу создания учебных пособий по образовательным программам ФГОС по направлению 51.04.04 «Музеология и охрана объектов культурного и природного наследия» (магистратура) и ФГОС по направлению 51.03 .04 «Музеология и охрана объектов культурного и природного наследия» (бакалавриат), считая их выход важным не только для обеспечения учебного процесса, но и для формулирования концептуальных основ подготовки новой гене- 
рации музейных работников с учетом традиций формирующейся научной школы петербургской музеологии ${ }^{1}$.

Чрезвычайно актуальным представлялось написание учебного пособия прежде всего для студентов, обучающихся в магистратуре, поскольку данная ступень впервые была введена в систему высшего образования постсоветской России с 2010 г. и имела целый ряд инновационных требований к его проектированию и практической реализации ${ }^{2}$.

В рамках образовательной программы ФГОС по направлению 51.04.04 «Музеология и охрана объектов культурного и природного наследия» (магистратура) кафедра музеологии и культурного наследия Санкт-Петербургского государственного института культуры реализует профиль «Менеджмент и экспертиза культурного наследия». Исходя из этого был составлен учебный план, выполнению которого и призвано служить учебное пособие «Культурное наследие и музей в XXI веке» ${ }^{3}$, вышедшее в юбилейный год 100-летия института и 30-летия кафедры (рис. 1). В его создании принимали участие: доктор культурологии, профессор А.Н. Балаш, кандидат культурологии, доцент Ю.В. Зиновьева, кандидат культурологии, доцент А.Н. Куклинова, кандидат исторических наук, доцент Е.Н. Мастеница, доктор философских наук, профессор А.С. Мухин, кандидат педагогических наук, доцент Л.М. Шляхтина. Редактором издания является Е.Н. Мастеница, а редакторомсоставителем А.Н. Балаш.

Авторы были единодушны в мнении о том, что проблема сохранения и трансляции культурного наследия как никогда актуальна для современного

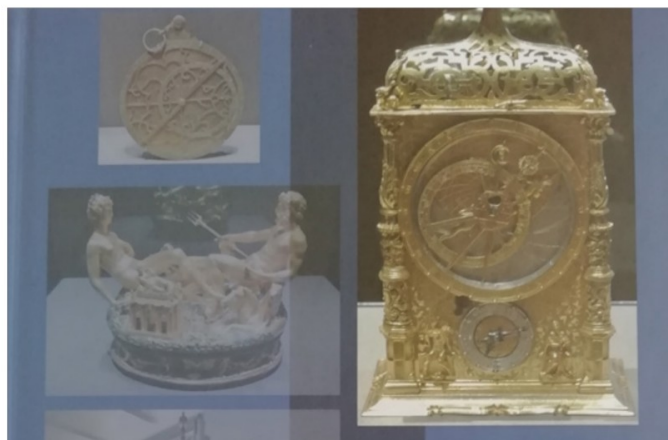
КУЛЬТУРНОЕ НАСЛЕДИЕ И МУЗЕЙ В ХХІ ВЕКЕ

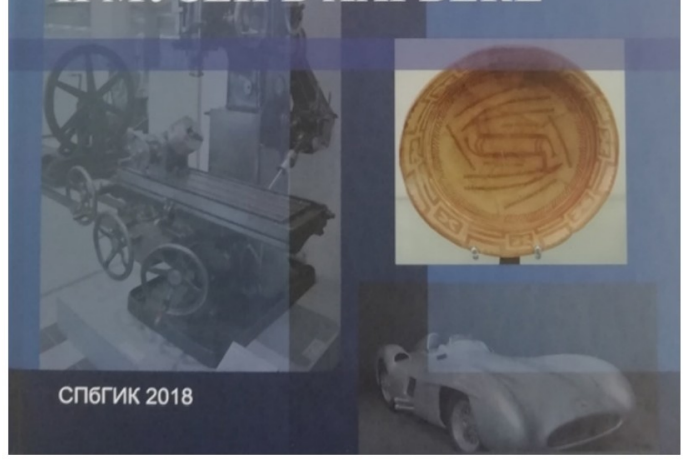

Pис. 1. Учебное пособие «Культурное наследие и музей в XXI веке». общества. Особую остроту ей придает нарастание темпов глобализации, радикально преобразующей реалии окружающего мира, изменяющей место в нем человека и роль личности в истории, а также пути и способы понимания и объяснения происходящего. Развитие интереса и повышенное внимание к сохранению материального и нематериального культурного наследия является следствием общенациональных и мировых цивилизационных процессов, связанных с сохранением этнической самобытности народов в условиях урбанизации и стандартизации жизни. Одним из вызовов современности рассматривается формирование т.н. «индустрии наследия», сопровождающееся коммерциализацией и консьюмеризмом, вследствие чего развивается сугубо утилитарное понимание памятников прошлого, деградации их до уровня рыночных продуктов социально-культурного потребления ${ }^{4}$. Обозначенная ситуация обусловила необходимость обращения к сущностным и функциональным характеристикам культурного

\footnotetext{
${ }^{1}$ Мастеница Е.Н., Шляхтина Л.М. Научные идеи и реалии практики как основа подготовки музейного специалиста в Санкт-Петербургском государственном институте культуры // Мировые тренды и музейная практика в России: сб. ст. Междунар. науч. конф. Москва, 30-31 октября 2018 г. М., 2019. С. 86-99.

${ }^{2}$ Мастеница Е.Н., Родионова Д.Д. Проблема проектирования содержания программы профессиональной подготовки специалистов-музеологов в магистратуре: опыт, условия, принципы // Вестник Кемеровского государственного института культуры. Журнал теоретических и прикладных исследований. 2018. C. 241-250.

${ }^{3}$ Культурное наследие и музей в ХХІ веке: учеб. пос. СПб., 2018.

${ }^{4}$ Мастеница Е.Н. Актуализация культурного наследия в музее: вызовы современности // Вестник Кемеровского государственного института культуры. Журнал теоретических и прикладных исследований. 2020 . № 50. С. 14-22.
} 
наследия, к способам его постижения, моделям его интерпретации и актуализации, подразумевающим не только физическое сохранение объектов наследия, но и активное включение их в пространство современной культуры.

В пособии обобщен и структурирован обширный материал, посвященный формированию представлений о наследии и музее, их исторической взаимосвязи и взаимообусловленности. Фокус внимания сосредоточен на происходящих сегодня трансформациях традиционных культурных институций. Особый акцент сделан на современные ценностно ориентированные тенденции развития отношения к наследию, а также на мировоззренческий постулат, связанный с пониманием культурного наследия как фундамента и важнейшего механизма функционирования культуры. Учебное пособие «является не столько компендиумом устоявшихся взглядов и общепринятых положений, сколько отражением состояния научного знания в сфере освоения наследия, систематизированного и изложенного с учетом исследовательских позиций и интересов его авторов» ${ }^{5}$ В силу этого многие материалы, включая не введенные ранее в научный оборот и не переведенные на русский язык труды зарубежных исследователей, обладают научной новизной.

Музеология и сфера наследия включают в себя множество тем и проблем. Изложить их все в одном учебном пособии - задача неразрешимая, да и ненужная. В основе учебного пособия «Культурное наследие и музей в XXI веке» лежит системный подход к пониманию феноменов культурного наследия и музея. Организация содержания базируется на системообразующих понятиях, овладение которыми обеспечивает возможность самостоятельного усвоения более частного материала, связанного с различными видами наследия, профильными группами музеев, разнообразными формами учреждений музейного типа. Этот же подход позволяет избежать методологической односторонности. Будучи не столько общенаучным методом, сколько философским пониманием действительности, системный взгляд в последнее время получил новый импульс развития на основе синергетического истолкования динамики самоорганизующихся сверхсложных систем, к числу которых относится и культура. Данное учебное пособие впервые излагает проблемы культурного наследия и музея в обозначенном ракурсе.

Системный подход позволяет трактовать наследие как антропо-социо-культурную систему, детерминирующую появление и развитие музейных институций. Наследие представляет собой устойчиво функционирующую длительное время систему, но одновременно подверженную множеству вызовов и угроз техногенного, экогенного, социогенного и антропогенного характера. Поэтому авторов данного учебного пособия объединяла идея о многоуровневой ценности культурного наследия как одного из важнейших ресурсов, влияющих на дальнейшее развитие личности, общества, региона, страны, поскольку оно является всеобъемлющим, достоверным и образным носителем информации о прошлом. Авторы предприняли попытку показать далеко не полностью осмысленный и тем более реализованный потенциал культурного наследия, методологический арсенал подходов к его изучению, многообразие практик управления наследием, способов его сохранения и интерпретации в музейном пространстве.

Структура книги включает в себя Предисловие, четыре главы, Заключение, список использованных сокращений и иллюстрации. Каждая глава завершается вопросами для самопроверки, заданиями для творческих работ, основным и дополнительным списками рекомендуемой литературы. «Красной нитью» книги является представление о наследии как субъекте динамического изменения. В первой главе (автор раздела «История и методология изучения культурного наследия» - Е.Н. Мастеница) рассматривается «историческая взаимообусловленность наследия и музея, существование многоаспектных взаимосвязей музея с процессом сохранения и трансляции материального и нематериального культурного наследия» ${ }^{6}$. Сегодня преодолено понимание нематериального наследия только как дополнительного, расширительного компонента сохраняемых в музеях артефактов культуры.

\footnotetext{
${ }^{5}$ Культурное наследие и музей в XXI веке... С. 5.

${ }^{6}$ Там же. С. 23.
} 
На рубеже XX-XXI вв. оно справедливо приобрело статус самостоятельного объекта музеефикации и вошло в круг проблем музеологии (автор раздела «Нематериальное культурное наследие» - Е.Н. Мастеница).

В пособии выявлен и продемонстрирован широкий спектр современных научных взглядов на вещь в контексте культуры (автор раздела - А.Н. Балаш), убедительно показана специфика архитектуры как одного из наиболее репрезентативных объектов наследия (автор раздела - А.С. Мухин). Специального внимания удостоены современные векторы развития исторической музеологии, подвергнут анализу аксиологический потенциал новой музеологии, провозгласившей отказ от элитарности музейной институции и предложившей модель экомузея (автор разделов - И.А. Куклинова). Рассмотрена миссия музея в социокультурных реалиях XXI в., в теоретическом ракурсе раскрыты актуальные тенденции развития музеев как институтов социальной памяти и агентов социального влияния (авторы раздела - Е.Н. Мастеница, Л.М. Шляхтина), что позволило обозначить методику экспертизы многообразных культурно-образовательных практик музея, направленных на интерпретацию наследия (автор раздела - Л.М. Шляхтина). В соответствии с нормами международного права и российским законодательством каждый объект культурного наследия представляет собой уникальную ценность для всего многонационального народа Российской Федерации и является неотъемлемой частью всемирного культурного наследия. Поэтому профессиональная деятельность в сфере охраны и использования объектов культурного наследия, реализация проектов их музеефикации требует уверенных знаний нормативноправовой базы, а также формирования компетенций в области охраны, менеджмента и актуализации культурного наследия, особенно в отношении музеев и учреждений музейного типа (автор раздела «Охрана и управление наследием» - Ю.В. Зиновьева). Как отмечает рецензент учебного пособия О.С. Сапанжа, «авторы ведут разговор об актуальных тенденциях, подчеркивая постоянную динамику научного и практического дискурсов, подвижность процессов трансформации музейного организма, стратегий его развития» ${ }^{7}$.

Несмотря на индивидуальный стиль повествования авторам разделов удалось найти «золотую середину» в манере изложения: формулировки и рассуждения не страдают научным академизмом и в то же время в них отсутствует упрощенность, порой приводящая к схематизму. Отказ от дидактизма и рецептурности позволяет уяснить суть изучаемых феноменов, раскрыть потенциал музеологии в ракурсе освоения материального и нематериального культурного наследия, показать музейную деятельность как разноплановую сферу, требующую от профессионала одновременно аналитических и творческих качеств.

С одной стороны, такая позиция авторского коллектива должна способствовать изменению бытующих представлений о музейных профессиях как уходящих в прошлое «хранителей старины» в связи с переходом к использованию информационных технологий. С другой стороны, очевидно стремление максимально разбудить самостоятельное мышление читателей, подготовить их к альтернативному выбору, к формированию собственных представлений и суждений.

Отметим, что в пособии присутствует репрезентативный ссылочный аппарат. Постраничные ссылки содержат значительный массив дополнительной библиографии и информации научного характера. Вынесенная за пределы основного текста, она предоставляет пытливому и внимательному читателю большие возможности для самостоятельного развития кругозора и эрудиции.

\footnotetext{
${ }^{7}$ Сапанжа О.С. Актуальная музеология в диалоге с историей, философией, проблемами наследия: о чем писали петербургские музеологи в 2018 г. // Вопросы музеологии. Междунар. науч. журнал. 2020. Т. 10. Вып. 2. С. 150.
} 
Как пишет О.С. Сапанжа, «традиционно формат учебного пособия предполагает, что в нем излагаются известные факты, термины и дефиниции науки/знания в области профессиональной деятельности, однако представляемое пособие носит иной характер. Перед нами не учебное пособие в классическом понимании, а определение актуальных контуров проблемного поля наследия в связи с музеем и музеологией» ${ }^{8}$.

В рамках образовательной программы ФГОС 51.03.04. «Музеология и охрана объектов культурного и природного наследия» (бакалавриат) кафедра музеологии и культурного наследия реализует профиль «Проектирование музейных экспозиций и выставок». В помощь студентам было подготовлено учебное пособие «Проектирование музейных экспозиций и выставок: история теория - практика» ${ }^{9}$. Над ним трудились: доктор культурологии, профессор А.Н. Балаш, старший преподаватель Е.И. Бородина, кандидат культурологии, доцент И.А Куклинова, кандидат исторических наук, доцент Е.Н. Мастеница, доктор философских наук, профессор А.С. Мухин, кандидат культурологии, доцент М.Н. Чеснокова. Редактор пособия - Е.Н. Мастеница, редакторсоставитель - А.Н. Балаш (рис. 2).

«Осью» книги является постулат о том, что предметный мир культуры, памятники истории и уникальные природные объекты составляют специфическую область музеологии как науки и практической деятельности музеев различного масштаба, вида и профиля, количество которых неуклонно возрастает. Музеи служат не только местом сосредоточения, но и местом представления предметного мира культуры разных эпох. Главным каналом реализации музейной коммуникации является экспозиция или выставка, позволяющие перенести и погрузить посетителя в уникальную систему «мира вещей» и «мира идей» как целостной модели культуры. Таким образом, музей, выступая как пространство актуальных смыслов, ценностей и сакральных объектов, представляет их обществу с помощью экспозиции в виде специально созданной среды или демонстрационной площадки и одновременно как специфического способа трансляции материального и нематериального наследия.

Пособие фундировано проработкой значительного корпуса специальной литературы, включая самые современные публикации как отечественных, так и зарубежных исследователей. На основе обобщения и систематизации различных точек зрения формулируются положения о том, что музейная экспозиция или выставочный проект становятся визуальнопространственным сообщением, содержание которого предназначено для посетителя и раскрывается при непосредственном его взаимодействии с объектами наследия. Именно они, обнаруженные в ходе раскопок археологические памятники, дошедшие до наших дней предметы старины, произведения искусства, мемории, связанные с выдающимися историческими личностями, памятники науки и техники, разнообразные естественно-научные коллекции, которые могут служить первоисточниками знаний и впечатлений о фактах, событиях и явлениях прошлого и современности, составляют основу музейной коммуникации. Технологический прогресс неуклонно следует вперед, предлагая все новые способы организации музейного пространства с применением информационно-коммуникационных

\footnotetext{
${ }^{8}$ Сапанжа О.С. Актуальная музеология... С. 149.

${ }^{9}$ Проектирование музейных экспозиций и выставок: история - теория - практика: учеб.-метод. пос. СПб., 2020.
} 
технологий, однако приоритет аутентичного музейного предмета, подлинника сохраняется неизменным.

Экспозиция, являясь основным каналом музейной коммуникации и своеобразным «лицом» музея, выступает мощным интегрирующим фактором всей музейной работы, в большей своей части скрытой от глаз музейной аудитории, потому что в ней наглядно проявляется взаимосвязь научно-исследовательской, фондовой и проектной деятельности в музее. Музейная экспозиция - это своеобразная «искусственная среда», где хранящиеся в музее предметы, изъятые из бытования и вырванные из контекста культуры, формируют новый текст и становятся музейными предметами или объектами в статусе экспонатов. Их совокупность в экспозиции образует знаковую систему, в которой заключены культурные коды с социально значимой информацией. Диалогичность музейной экспозиции помогает посетителю оценивать соответствующий текст и актуализировать зашифрованную в экспонатах информацию. Современный подход предполагает, что в процессе проектирования экспозиционер, подобно режиссеру, должен профессионально разработать и предложить такой способ организации пространства, который подталкивает посетителя к актуализации информации, заложенной в экспозиционном комплексе или выставочном ансамбле, способствуя погружению в эпоху или вживанию в ситуацию, дает импульс сопереживанию и, возможно, сотворчеству.

Тематика музейного собрания предопределяет содержание музейной экспозиции, а ее научная концепция и архитектурно-художественное решение позволяют раскрыть информационный и образовательный потенциал музейного предмета, а также говорят об осмыслении и реализации возложенной на музей социокультурной миссии, во многом определяя его имидж и статус в городе, регионе, стране и в мире.

Учебное пособие призвано помочь постижению сути современной музейной экспозиции и выставки, которые являются не только способом репрезентации культурного наследия, отражением уровня научных знаний в той или иной области мировой культуры, но и значимым социокультурным проектом, а также изучению научных подходов и технологий их проектирования. Книга состоит из введения, трех разделов, заключения и иллюстраций. Каждый параграф внутри раздела завершает список рекомендованной литературы, контрольные вопросы и задания для самостоятельного выполнения.

Структура учебного пособия четко обозначена в его названии. Первый раздел «История выставочной деятельности» (автор - И.А. Куклинова) позволяет приобщиться к предыстории выставочной деятельности и узнать, как проходили и чему были посвящены музейные выставки в XX в. Изучение основных тенденций в ретроспективном ключе дает возможность освоить богатый опыт выставочного строительства на примере Всемирных, мануфактурных и художественных выставок, что позволяет современному специалисту уверенно смотреть в будущее, смело проектируя новые музейные пространства. Мир музейных выставок, как и их задачи, чрезвычайно разнообразен. История убедительно свидетельствует, что в момент создания нового музея он часто начинает свои экспозиционные искания, организуя временные выставки. Связано это может быть как с отсутствием или начальным этапом формирования фондов, так и с новизной материала, который предстоит документировать и популяризировать. Временные выставки занимают прочное место в музеях различного профиля в конце XIX - начале XX в., а возводимые новые музейные здания обязательно предполагают специальные залы для их проведения. Однако длительное время к ним относились как к краткому, недолговечному явлению в жизни музея, обращенному в первую очередь на работу с коллекциями и создание постоянной экспозиции.

Одним из наиболее ярких свидетельств трансформации музейной институции становится активизация выставочной деятельности в XX в., затронувшая как крупнейшие мировые сокровищницы искусства, так и скромные региональные собрания. В настоящее время эта тенденция достигла своего апогея, а выставка стала не только одним из важнейших показателей отчетности о деятельности музея, но и одним из главных мотивов его посещения. 
Второй раздел «Основы научного проектирования музейных экспозиций и выставок» (авторы - А.Н. Балаш, М.Н. Чеснокова, И.А. Куклинова, Е.Н. Мастеница) раскрывает методы построения музейных экспозиций, принципы отбора экспонатов и использования экспозиционных материалов, освещает вопросы документального оформления научной концепции экспозиции, а также специфику выставочной деятельности в литературных и естественно-научных музеях, которым, как правило, уделяется меньше внимания, чем историческим. Объясняется популярность столь востребованных в наше время концептуальных музейных выставок и кураторских проектов.

«Красной нитью» учебного пособия является объяснение того, что современная музейная экспозиция и выставка являются особым синтетическим научно-художественным произведением, которое создается в соответствии с единым идейным замыслом, определяющим принцип отбора, группировку и интерпретацию экспонатов на основе научного, сценарного и художественно-дизайнерского решения. Являясь основным каналом и центральным звеном музейной коммуникации, музейная экспозиция может быть в соответствии с семиотическим подходом рассмотрена как многоуровневый текст. В силу социального запроса экспозиция создается как образовательный проект, зачастую предусматривающий инклюзивное образование, а в рамках экономического подхода выступает как основной музейный продукт. В любом случае - экспозиция - это лицо современного музея, она задает планку его привлекательности для публики и во многом определяет его роль и значение в культурном пространстве города, региона, страны. Выставка во всем многообразии ее жанров позволяет не только дополнить стационарную экспозицию музея, но и раскрыть фондовые собрания для посетителей, показать новые поступления, вспомнить о юбилейном событии, поднять актуальную тему, иными словами, решить широкий спектр социокультурных задач.

Концептуальная выставка - это всегда взаимодействие, «беседа» между автором произведений и зрителем, куратором выставки и посетителем, из пассивного наблюдателя превращающимся в активного исследователя и творца смыслов. Роль посетителя выставки становится активной, и отнюдь не потому, что этот человек вовлекается в хеппенинг, партиципаторные практики, взаимодействует с интерактивными объектами. Активная роль посетителя как сотворца, собеседника куратора и автора произведений формируется благодаря тщательно разработанной самобытной концепции, воплощенной средствами экспозиционного дизайна и проектирования в целостном и активно воздействующем на восприятие художественном решении.

Третий раздел «Организация экспозиционно-выставочного пространства» (авторы А.С. Мухин, Е.И. Бородина) педалирует идею о том, что проектирование музейных экспозиций и выставок невозможно без прочного теоретического фундамента, помогающего постижению архитектоники экспозиционно-выставочного пространства, освоению методов его построения, верному выбору принципов создания, отбору предметов для презентации с учетом множества технологических требований, в т.ч. и применения информационнокоммуникационных технологий и мультимедиа.

Авторы учебного пособия полагают, что экспозиционно-выставочное пространство в музее - весьма эластичная и динамично развивающаяся субстанция. При умелом проектировании оно, с одной стороны, приобретает различные формы, наполненные конкретным содержанием, которое определяется тематикой и составом музейного собрания, а с другой, следуя от нейтральности и к музейному образу, превращается в особый вид искусства. В отличие от прежде царивших убеждений сегодня важно осознать, что экспозиционер работает не только с предметом, но и с пространством, временем, светом, цветом, звуком, движением. В тесной взаимосвязи всех этих компонентов между собой и одновременном взаимодействии с музейной аудиторией рождается современная музейная экспозиция.

Еще пару десятилетий назад авторские экспозиции и выставки вызывали настороженность и неоднозначную оценку как музейных специалистов, так и публики. В наши дни осознание того, что музейное проектирование - это искусство, соединяющее науку, 
элементы архитектурного проектирования, художественного и технического конструирования, декоративного творчества, театральной драматургии, сценографии - является прямым путем к признанию и успеху.

Авторы пособия на широком круге конкретных примеров стремились показать, что экспозиционно-выставочная деятельность - это широкое поле для основанного на профессиональных знаниях творчества, которое включает научно достоверное содержание, архитектурно-пространственную организацию экспозиционных материалов, конструктивное построение и специальное оборудование, цветовое и световое решение, создание образа и т.п. на основе художественно-композиционных принципов и приемов. Именно образновыразительная составляющая экспозиции задает вектор ее восприятия, обеспечивает ее коммуникативность, эмоциональное воздействие и высокий уровень решения функциональных задач, связанных с сохранностью и презентацией экспонатов.

Современная практика освоения наследия фиксирует адаптивность и гибкость музейной среды: музеефикации и репрезентации подвергаются не только материальные предметы, но и нематериальное культурное наследие, культурный ландшафт и урбанизированные локусы. Экспозиционно-выставочное пространство неуклонно раздвигает свои границы и становится максимально доступным в самом широком толковании этого слова. Сложные исторические, художественные и природные процессы визуализируются, в т.ч. и при помощи мультимедийных инсталляций, а также других новейших способов передачи информации. Музейная практика стимулирует интенсивное развитие музеологической мысли, понятийнотерминологического аппарата, особенно в области теории музейного предмета и музейной коммуникации, лежащих в основе проектирования музейных экспозиций и выставок, что нашло отражение в учебном пособии, предназначенном специалистам XXI в.

Изучение процесса проектирования музейных экспозиций и выставок в историческом, теоретическом и прикладном аспектах, по мнению коллектива авторов, должно способствовать профессионализации данного направления музейной деятельности. Изложенные основы проектирования предназначены новому поколению музеологов, способных отвечать вызовам времени, креативно мыслить и самостоятельно решать поставленные задачи.

Однако знакомство с архитектоникой экспозиционно-выставочного пространства и актуальными тенденциями экспонирования может быть полезно будущим историкам, культурологам, искусствоведам и всем, кто предполагает иметь или имеет отношение к музейному делу. Пособие окажется интересным и для музейных сотрудников со стажем, а также любопытным для тех читателей, кто не равнодушен к музеям и любит посещать выставки, проявляет живой интерес к тому, как должна выглядеть современная музейная экспозиция и что она может предложить публике сегодня.

В заключение отметим, что представленные на обозрение учебные пособия, написанные преподавателями кафедры музеологии и культурного наследия Санкт-Петербургского государственного института культуры, стали результатом размышлений и многолетних научных исследований авторов, получивших отражение в монографиях и многочисленных статьях, и одновременно итогом их апробации в процессе реализации образовательных программ бакалавриата и магистратуры по направлению «Музеология и охрана культурного и природного наследия», коллективных усилий по отработке учебно-методических аспектов преподавания и плодотворного сотрудничества с музеями Санкт-Петербурга в течение последних 10 лет.

\section{Лumepamypa}

Культурное наследие и музей в XXI веке: учеб. пос. / М-во культуры РФ, СПб. гос. ин-т культуры, фак. мировой культуры, каф. музеологии и культурного наследия; ред. Е.Н. Мастеница; ред.-сост. А.Н. Балаш. СПб.: СПБГИК, 2018. 248 с.

Мастеница E.Н. Актуализация культурного наследия в музее: вызовы современности // Вестник Кемеровского государственного института культуры. Журнал теоретических и прикладных исследований. 2020. № 50. С. 14-22. 
Мастеница E.H., Родионова Д.Д. Проблема проектирования содержания программы профессиональной подготовки специалистов-музеологов в магистратуре: опыт, условия, принципы // Вестник Кемеровского государственного института культуры. Журнал теоретических и прикладных исследований. 2018. № 43. С. 241-250.

Мастеница Е.Н., Шляхтина Л.M. Научные идеи и реалии практики как основа подготовки музейного специалиста в Санкт-Петербургском государственном институте культуры // Мировые тренды и музейная практика в России: сб. ст. Междунар. науч. конф. Москва, 30-31 октября 2018 г. / отв. ред. А.А. Сундиева. М.: РГГУ, 2019. С. 86-99.

Проектирование музейных экспозиций и выставок: история - теория - практика: учеб.методич. пос. / М-во культуры РФ. СПб. гос. ин-т культуры, фак. мировой культуры, каф. музеологии и культурного наследия; А.Н. Балаш, Е.И. Бородина, И.А. Куклинова и др.; ред. Е.Н. Мастеница; ред.-сост. А.Н. Балаш. СПб.: СПБГИК, 2020. 184 с.

Сапанжа O.C. Актуальная музеология в диалоге с историей, философией, проблемами наследия: о чем писали петербургские музеологи в 2018 г. // Вопросы музеологии. Междунар. науч. журнал. 2020. Т. 10. Вып. 2. С. 142-152.

\section{References}

Balash, A.N., Borodina, Ye.I., Kuklinova, I.A. et al. (2020). Proyektirovaniye muzeynykh ekspozitsiy i vystavok: istoriya - teoriya - praktika: uchebno-metodich. posobiye [Designing museum expositions and exhibitions: history-theory-practice: educational-methodical manual] / M-vo kul'tury RF. St. Peterb. gos. in-t kul'tury, fak. mirovoy kul'tury, kaf. muzeologii i kul'turnogo naslediya. St. Petersburg, $184 \mathrm{p}$.

Mastenitsa, E.N. (Ed.) (2018). Kul'turnoye naslediye i muzey $v$ XXI veke: ucheb. posobiye [Cultural heritage and museum in the $21^{\text {st }}$ century: textbook] / M-vo kul'tury RF, St. Peterb. gos. in-t kul'tury, fak. mirovoy kul'tury, kaf. muzeologii i kul'turnogo naslediya; St. Petersburg. 248 p.

Mastenitsa, E.N. (2020). Aktualizatsiya kul'turnogo naslediya v muzeye: vyzovy sovremennosti [Updating the cultural heritage in the museum: modern challenges]. In Vestnik Kemerovskogo gosudarstvennogo instituta kultury. Zhurnal teoreticheskikh i prikladnykh issledovaniy. No. 50, pp. 14-22.

Mastenitsa, E.N., Rodionova, D.D. (2018). Problema proyektirovaniya soderzhaniya programmy professional'noy podgotovki spetsialistov-muzeologov v magistrature: opyt, usloviya, printsipy [The problem of creating the content of the professional training program for museologists in the magistracy: experience, conditions, principles]. In Vestnik Kemerovskogo gosudarstvennogo instituta kul'tury. Zhurnal teoreticheskikh i prikladnykh issledovaniy. No. 43, pp. 241-250.

Mastenitsa, E.N., Shlyakhtina, L.M. (2019). Nauchnyye idei i realii praktiki kak osnova podgotovki muzeynogo spetsialista v Sankt-Peterburgskom gosudarstvennom institute kul'tury [Scientific ideas and realities of practice as a basis for training museum specialists at the St. Petersburg State Institute of Culture]. In Sundiyeva A.A. (Ed.). Mirovyye trendy i muzeynaya praktika $v$ Rossii: Sbornik Mezhdunar. nauch. konf. Moskva, 30-31 oktyabrya 2018 g. Moscow, pp. 86-99.

Sapanzha, O.S. (2020). Aktual'naya muzeologiya v dialoge s istoriyey, filosofiyey, problemami naslediya: o chem pisali peterburgskiye muzeologi v 2018 g. [Actual museology in dialogue with history, philosophy, heritage issues: what the Petersburg museologists wrote about in 2018]. In Voprosy muzeologii. Mezhdunarodnyy nauchnyy zhurnal. Vol. 10. Iss. 2, pp. 142-152.

Статья поступила в редакцию 05.01.2021 г. 